
\title{
$\begin{array}{ll}\text { Research Square } & \begin{array}{l}\text { Preprints are preliminary reports that have not undergone peer review. } \\ \text { They should not be considered conclusive, used to inform clinical practice, } \\ \text { or referenced by the media as validated information. }\end{array}\end{array}$
}

\section{Clinicopathological Characteristics and Survival Outcomes in Patients with Synchronous Lung Metastases Upon Initial Metastatic Breast Cancer Diagnosis in Han Population}

\section{Shaoyan Lin}

National Cancer Center/National Clinical Research Center for Cancer/Cancer Hospital, Chinese Academy of Medical Sciences \& Peking Union Medical College

Hongnan Mo

National Cancer Center/National Clinical Research Center for Cancer/Cancer Hospital, Chinese Academy of Medical Sciences \& Peking Union Medical College

\section{Yiqun Li}

National Cancer Center/National Clinical Research Center for Cancer/Cancer Hospital, Chinese Academy of Medical Sciences \& Peking Union Medical College

\section{Xiuwen Guan}

National Cancer Center/National Clinical Research Center for Cancer/Cancer Hospital, Chinese Academy of Medical Sciences \& Peking Union Medical College

\section{Yimeng Chen}

National Cancer Center/National Clinical Research Center for Cancer/Cancer Hospital, Chinese Academy of Medical Sciences \& Peking Union Medical College

\section{Zijing Wang}

National Cancer Center/National Clinical Research Center for Cancer/Cancer Hospital, Chinese Academy of Medical Sciences \& Peking Union Medical College

Binghe Xu ( $\nabla$ xubinghe@medmail.com.cn)

National Cancer Center/National Clinical Research Center for Cancer/Cancer Hospital, Chinese Academy of Medical Sciences \& Peking Union Medical College

\section{Research Article}

Keywords: Breast neoplasms, Lung, Neoplasm metastasis, Prognosis, Survival

Posted Date: August 4th, 2021

DOl: https://doi.org/10.21203/rs.3.rs-701307/v1 
License: (c) (i) This work is licensed under a Creative Commons Attribution 4.0 International License. Read Full License

Version of Record: A version of this preprint was published at BMC Cancer on December 1st, 2021. See the published version at https://doi.org/10.1186/s12885-021-09038-2. 


\section{Abstract \\ Background}

We investigated the clinicopathological characteristics and survival of breast cancer lung metastases (BCLM) patients at initial diagnosis of metastatic breast cancer (MBC) in the Han population.

\section{Methods}

We attained clinical data of $3155 \mathrm{MBC}$ patients initially diagnosed between April 2000 and September 2019 from the China National Cancer Center and finally included 2263 MBC patients in this study, among which 809 patients presented with lung metastases at first MBC diagnosis. The risk factors for BCLM were determined using multivariate logistic regression analysis and the prognostic factors of BCLM patients were assessed by univariate and multivariate Cox regression analyses.

\section{Results}

Patients with triple-negative subtype (42.3\%) harbored the highest incidence proportions of lung metastases. Age $\geq 50$ years, Eastern Cooperative Oncology Group (ECOG) 2 and triple-negative subtype were remarkably associated with higher incidence of lung metastases, while N3, liver and bone metastases were significantly correlated with lower odds of lung metastases at diagnosis. The median survival of BCLM patients was 41.7 months, with triple-negative subtype experiencing the worst prognosis of 26.8 months. ECOG 2, N3, hormone receptor-negative (HR-)/human epidermal growth factor receptor 2-positive (HER2) + subtype, triple-negative subtype, liver metastases and bone metastases were significantly correlated with poor survival of BCLM patients.

\section{Conclusions}

Our study provides essential information on clinicopathological features and survival outcomes of BCLM patients at initial diagnosis of MBC in China.

\section{Background}

Lung metastasis is the second most frequent distant metastases of breast cancer [1, 2], clinically presenting in $15-25 \%$ of metastatic breast cancer (MBC) patients [3, 4]. Autopsy data of 197 women dying with $\mathrm{MBC}$ over a period of 50 years revealed that $80.7 \%$ of patients had lung or pleura metastases [5]. A population-based study indicated that the median survival of 3372 patients with lung metastases at primary breast cancer diagnosis was 21 months [6]. Although the prognosis of MBC patients with metastases confined to lungs is not so poor as brains or livers [7], most patients are considered incurable and the treatment is still intractable. With an occult onset, lung metastases from breast cancer usually 
present asymptomatically and progress aggressively without appropriate care [8]. Systemic treatments including chemotherapy, targeted therapy and hormone therapy are recommended for patients with breast cancer lung metastases (BCLM) [9] and pulmonary metastasectomy is considerable for properly selected cases [10]. The early detection of lung metastasis and the precise estimation of outcome may benefit breast cancer patients in clinical practice, thus achieving long-term survival. However, the clinicopathological characteristics and the risk factors that affect the incidence and prognosis of BCLM remain poorly identified in the Han population.

In this article, we summarized the clinicopathological features and explored the risk factors associated with the morbidity and mortality of BCLM in newly diagnosed MBC patients in China, which may help identify cases with higher odds of lung metastases and worse survival. Early intervention and multidisciplinary treatment for BCLM patients are of utmost importance.

\section{Methods}

This work was approved by the institutional review board of National Cancer Center/National Clinical Research Center for Cancer/Cancer Hospital, Chinese Academy of Medical Sciences and Peking Union Medical College. All methods were carried out in accordance with relevant guidelines and regulations. The study methods referred to the previous report [11].

\section{Study population}

We attained clinical data of 3155 MBC patients initially diagnosed between April 2000 and September 2019 from the China National Cancer Center. We removed patients with unknown tumor receptor status (n $=579)$, unknown distant metastases $(n=65)$ and follow-up no more than 1 month since the initial diagnosis of MBC $(n=254)$ from this cohort, finally leaving 2263 patients for incidence analysis. Among these, 809 cases presented with lung metastases upon initial MBC diagnosis. Telephone calls or clinical visits were used to follow up patients further to June 30,2019 or date of their deaths.

\section{Study variables}

Study variables, including age at initial MBC diagnosis, Eastern Cooperative Oncology Group (ECOG) grade, TNM stage of primary breast cancer, tumor receptor status, metastatic sites and overall survival (OS) from the onset of metastasis to death were retrospectively collected from medical records in hospital information system. Cancers with $1 \%-100 \%$ estrogen receptor or progesterone receptor routine immunohistochemistry (IHC) staining were considered hormone receptor-positive (HR+). Human epidermal growth factor receptor 2 (HER2) overexpression was defined as IHC3+ or in the case of IHC2+, fluorescent in-situ hybridization (FISH) positive. Breast cancer subtypes were divided as HR+/HER2-, $\mathrm{HR}-/ \mathrm{HER} 2+, \mathrm{HR}+/ \mathrm{HER} 2+$ and triple-negative (HR-/HER2-). Tumor staging was based on the 8th American Joint Committee on Cancer (AJCC) TNM staging system.

\section{Statistical analysis}


Chi-square or Fisher's exact test were used for category variables to compare the clinicopathological features among different subtypes in patients with lung metastases. Incidence of lung metastases was defined as the number of BCLM patients divided by the total number of MBC patients. We performed multivariate logistic regression to explore factors associated with the presence of lung metastases upon initial diagnosis of MBC. We calculated odds ratios (ORs) and $95 \%$ confidence intervals (Cls) in the model. Kaplan-Meier method was utilized to estimate the survival within subsets and log-rank test was used to analyze the differences. We conducted univariate and multivariate Cox regression analyses to investigate the independent predictive factors significantly associated with the prognosis of BCLM patients. All the statistics were analyzed using SPSS statistical software version 23.0 package. A twosided $p$ value of 0.05 or less was significantly different.

\section{Results}

\section{Patient characteristics}

A total of $2263 \mathrm{MBC}$ patients were enrolled in final cohort, of which $35.7 \%$ (809) synchronously presented with lung metastases upon initial MBC diagnosis and Table 1 listed their clinicathological characteristics stratified by breast cancer subtype. It showed that $15.1 \%$ (122) of BCLM patients were diagnosed with de novo metastatic disease. BCLM patients with HR+/HER2-, HR-/HER2+, HR+/HER2 + and triple-negative subtypes accounted for $47.7 \%, 14.3 \%, 16.1 \%$ and $21.9 \%$, respectively. Compare with other subsets, triplenegative patients with lung metastases were younger $(p=0.015)$, had a earlier $\mathrm{N}$-stage of primary breast cancer $(p=0.005)$, presented with more recurrent diseases $(p=0.002)$ and less liver metastases $(p=$ 0.001). HER2+ (HR-/HER2 + and HR+/HER2+) patients with BCLM were more frequently diagnosed with de novo stage IV breast cancer than HER2- (HR+/HER2- and triple-negative) patients $(p=0.002)$. BCLM patients with HR+/HER2- subtype had the highest rate of bone metastases $(p=0.000)$. 
Table 1

Clinicopathological characteristics of patients with lung metastases upon initial metastatic breast cancer diagnosis according to breast cancer subtype

\begin{tabular}{|c|c|c|c|c|c|}
\hline Characteristic & $\begin{array}{l}\text { HR+/HER2-, } \\
\mathrm{N}(\%)\end{array}$ & $\begin{array}{l}\text { HR-/HER2+, } \\
\mathrm{N}(\%)\end{array}$ & $\begin{array}{l}\text { HR+/HER2+, } \\
\mathrm{N}(\%)\end{array}$ & $\begin{array}{l}\text { Triple-negative, } \\
\mathrm{N}(\%)\end{array}$ & $p$ value \\
\hline All patients & $386(47.7)$ & $116(14.3)$ & $130(16.1)$ & $177(21.9)$ & \\
\hline Age & & & & & 0.015 \\
\hline$<50$ & $172(44.6)$ & $44(37.9)$ & $62(47.7)$ & 99 (55.9) & \\
\hline$\geq 50$ & $214(55.4)$ & $72(62.1)$ & $68(52.3)$ & $78(44.1)$ & \\
\hline ECOG & & & & & 0.194 \\
\hline 0 & $91(23.6)$ & $24(20.7)$ & $23(17.7)$ & $46(26.0)$ & \\
\hline 1 & $278(72.0)$ & $88(75.9)$ & $102(78.5)$ & $117(66.1)$ & \\
\hline 2 & $17(4.4)$ & $4(3.4)$ & $5(3.8)$ & $14(7.9)$ & \\
\hline T-stage & & & & & 0.065 \\
\hline $\mathrm{T} 1$ & $104(26.9)$ & $24(20.7)$ & $32(24.6)$ & $47(26.6)$ & \\
\hline $\mathrm{T} 2$ & $169(43.8)$ & $50(43.1)$ & $52(40.0)$ & $83(46.9)$ & \\
\hline T3 & $20(5.2)$ & $6(5.2)$ & $5(3.8)$ & $17(9.6)$ & \\
\hline $\mathrm{T} 4$ & $18(4.7)$ & $12(10.3)$ & $9(6.9)$ & $6(3.4)$ & \\
\hline Unknown & 75 (19.4) & $24(20.7)$ & $32(24.6)$ & $24(13.6)$ & \\
\hline $\mathrm{N}$-stage & & & & & 0.005 \\
\hline NO & $113(29.3)$ & $25(21.6)$ & $30(23.1)$ & $65(36.7)$ & \\
\hline N1 & $96(24.9)$ & $23(19.8)$ & $43(33.1)$ & $45(25.4)$ & \\
\hline N2 & $66(17.1)$ & $22(19.0)$ & $23(17.7)$ & 31 (17.5) & \\
\hline N3 & $67(17.4)$ & $35(30.2)$ & $20(15.4)$ & 19 (10.7) & \\
\hline Unknown & $44(11.4)$ & $11(9.5)$ & $14(10.8)$ & $17(9.6)$ & \\
\hline M-stage & & & & & 0.002 \\
\hline MO & $339(87.8)$ & $88(75.9)$ & $103(79.2)$ & $157(88.7)$ & \\
\hline M1 & $47(12.2)$ & $28(24.1)$ & $27(20.8)$ & $20(11.3)$ & \\
\hline Liver metastases & & & & & 0.001 \\
\hline
\end{tabular}




\begin{tabular}{|c|c|c|c|c|c|}
\hline Characteristic & $\begin{array}{l}\text { HR+/HER2-, } \\
\mathrm{N}(\%)\end{array}$ & $\begin{array}{l}\text { HR-/HER2+, } \\
N(\%)\end{array}$ & $\begin{array}{l}\text { HR+/HER2+, } \\
N(\%)\end{array}$ & $\begin{array}{l}\text { Triple-negative, } \\
\mathrm{N}(\%)\end{array}$ & $p$ value \\
\hline No & $308(79.8)$ & $85(73.3)$ & $88(67.7)$ & $152(85.9)$ & \\
\hline Yes & $78(20.2)$ & $31(26.7)$ & $42(32.3)$ & $25(14.1)$ & \\
\hline Brain metastases & & & & & 0.625 \\
\hline No & $370(95.9)$ & $108(93.1)$ & $124(95.4)$ & $170(96.0)$ & \\
\hline Yes & $16(4.1)$ & $8(6.9)$ & $6(4.6)$ & $7(4.0)$ & \\
\hline Bone metastases & & & & & 0.000 \\
\hline No & $226(58.5)$ & $91(78.4)$ & $89(68.5)$ & $134(75.7)$ & \\
\hline Yes & $160(41.5)$ & $25(21.6)$ & $41(31.5)$ & $43(24.3)$ & \\
\hline
\end{tabular}

Table 2 displayed the incidence of patients with lung metastases stratified by breast cancer subtype. HR+/HER2-, HR-/HER2+, HR+/HER2 + and triple-negative subtypes accounted for $52.1 \%, 13.3 \%, 16.1 \%$ and $18.5 \%$ of the entire MBC population, respectively. Patients with triple-negative subtype $(42.3 \%)$ harbored the highest incidence proportions of lung metastases.

Table 2

Incidence of patients with lung metastases at first metastatic breast cancer diagnosis stratified by breast cancer subtype

\begin{tabular}{|llll|}
\hline & $\begin{array}{l}\text { All metastatic patients, } \mathbf{N} \\
(\%)\end{array}$ & $\begin{array}{l}\text { With lung } \\
\text { metastases }\end{array}$ & $\begin{array}{l}\text { Incidence of lung metastases, } \\
\%\end{array}$ \\
\hline HR+/HER2- & $1180(52.1)$ & 386 & 32.7 \\
\hline HR-/HER2+ & $300(13.3)$ & 116 & 38.6 \\
\hline HR+/HER2+ & $365(16.1)$ & 130 & 35.6 \\
\hline $\begin{array}{l}\text { Triple- } \\
\text { negative }\end{array}$ & $418(18.5)$ & 177 & 42.3 \\
\hline All subtypes & $2263(100.0)$ & 809 & 35.7 \\
\hline HR hormone receptor, HER2 human epidermal growth factor receptor 2. \\
\hline
\end{tabular}

Association between the presence of lung metastases at initial MBC diagnosis and variables assessed by multivariate logistic regression was showed in Table 3 . Age $\geq 50$ years (vs. $<50$ years, $\mathrm{OR}=1.32,95 \% \mathrm{Cl}$ 
$=1.11-1.57, p=0.002$ ), ECOG 2 (vs. ECOG 0, OR = 1.66, 95\% Cl =1.04-2.63, $p=0.034$ ), and triple-negative subtype (vs. HR+/HER2-, OR $=1.43,95 \% \mathrm{Cl}=1.13-1.81, p=0.003$ ) were remarkably associated with higher incidence of lung metastases at diagnosis. N3 (vs. N0, OR $=0.75,95 \% \mathrm{Cl}=0.57-0.99, p=0.045$ ), liver metastases (vs. without liver metastases, $\mathrm{OR}=0.78,95 \% \mathrm{Cl}=0.63-0.96, p=0.021$ ) and bone metastases (vs. without bone metastases, $\mathrm{OR}=0.75,95 \% \mathrm{Cl}=0.62-0.91, p=0.003$ ) were significantly correlated with lower odds of lung metastases at diagnosis. 
Table 3

Multivariate logistic regression for the presence of lung metastases at initial diagnosis of metastatic breast cancer

\begin{tabular}{|c|c|c|}
\hline Characteristic & OR $(95 \% \mathrm{Cl})$ & $p$ value \\
\hline \multicolumn{3}{|l|}{ Age } \\
\hline$<50$ & Reference & \\
\hline$\geq 50$ & $1.32(1.11,1.57)$ & 0.002 \\
\hline \multicolumn{3}{|l|}{ ECOG } \\
\hline 0 & Reference & \\
\hline 1 & $1.17(0.95,1.44)$ & 0.143 \\
\hline 2 & $1.66(1.04,2.63)$ & 0.034 \\
\hline \multicolumn{3}{|l|}{ T-stage } \\
\hline T1 & Reference & \\
\hline $\mathrm{T} 2$ & $1.03(0.83,1.29)$ & 0.771 \\
\hline T3 & $0.74(0.50,1.10)$ & 0.136 \\
\hline $\mathrm{T} 4$ & $1.28(0.81,2.02)$ & 0.290 \\
\hline Unknown & $0.83(0.62,1.11)$ & 0.202 \\
\hline \multicolumn{3}{|l|}{$\mathrm{N}$-stage } \\
\hline NO & Reference & \\
\hline N1 & $1.02(0.80,1.29)$ & 0.906 \\
\hline N2 & $0.91(0.69,1.19)$ & 0.476 \\
\hline N3 & $0.75(0.57,0.99)$ & 0.045 \\
\hline Unknown & $1.07(0.74,1.54)$ & 0.718 \\
\hline \multicolumn{3}{|l|}{ M-stage } \\
\hline MO & Reference & \\
\hline M1 & $1.08(0.82,1.42)$ & 0.597 \\
\hline \multicolumn{3}{|l|}{ Subtype } \\
\hline HR+/HER2- & Reference & \\
\hline HR-/HER2+ & $1.26(0.96,1.66)$ & 0.096 \\
\hline
\end{tabular}

OR odds ratio, Cl confidence interval, ECOG Eastern Cooperative Oncology Group, HR hormone receptor, HER2 human epidermal growth factor receptor 2. 


\begin{tabular}{|lll|}
\hline Characteristic & OR $(95 \% \mathrm{Cl})$ & $p$ value \\
\hline HR+/HER2+ & $1.16(0.90,1.49)$ & 0.262 \\
\hline Triple-negative & $1.43(1.13,1.81)$ & 0.003 \\
\hline Liver metastases & & \\
\hline No & Reference & 0.021 \\
\hline Yes & $0.78(0.63,0.96)$ & \\
\hline Brain metastases & & 0.613 \\
\hline No & Reference & \\
\hline Yes & $1.12(0.72,1.73)$ & \\
\hline Bone metastases & & 0.003 \\
\hline No & Reference & \\
\hline Yes & $0.75(0.62,0.91)$ & \\
\hline $\begin{array}{l}\text { OR odds ratio, Cl confidence interval, ECOG Eastern Cooperative Oncology Group, HR hormone } \\
\text { receptor, HER2 human epidermal growth factor receptor 2. }\end{array}$ & \\
\hline
\end{tabular}

\section{Survival}

The median survival among the whole MBC cohort was 45.4 months, with a median follow-up of 61.6 months. Figure 1 showed that the prognosis of patients with lung metastases upon MBC diagnosis (median OS, 41.7 months) was significantly worse than those without lung metastases (median OS, 47.9 months, $p=0.001$ ). Figure 2 provided the survival of BCLM patients according to breast cancer subtype. The survival of BCLM patients with HR+/HER2- subtype (49.0 months) was the longest, while triplenegative (26.8 months, $p=0.000$ ) the shortest. BCLM patients with HR-/HER2+ (vs. HR+/HER2-, $p=0.009)$ and HR+/HER2+ (vs. HR+/HER2-, $p=0.746$ ) subtypes experienced the median OS of 31.6 and 44.1 months, respectively.

The prognostic factors of BCLM patients assessed by univariate and multivariate Cox regression analyses were presented in Table 4. The significant variables with $p$ value $<0.05$ in univariate analysis were further included in multivariate Cox regression model. ECOG 2 (vs. ECOG 0, HR $=1.71,95 \% \mathrm{Cl}=$ $1.10-2.68, p=0.018$ ), N3 (vs. N0, HR $=1.43,95 \% \mathrm{Cl}=1.05-1.95, p=0.023), \mathrm{HR}-/ \mathrm{HER} 2+$ subtype (vs. HR+/HER2-, HR = 1.44, 95\% Cl = 1.07-1.94, $p=0.016$ ), triple-negative subtype (vs. HR+/HER2-, HR = 1.96, $95 \% \mathrm{Cl}=1.52-2.52, p=0.000$ ), liver metastases (vs. without liver metastases, $\mathrm{HR}=2.57,95 \% \mathrm{Cl}=2.05-$ $3.21, p=0.000$ ) and bone metastases (vs. without bone metastases, $\mathrm{HR}=1.33,95 \% \mathrm{Cl}=1.08-1.64, p=$ 0.007 ) were significantly correlated with poor survival of BCLM patients. 
Page $11 / 20$ 
Table 4

Univariate and multivariate cox regression analyses of OS in BCLM patients

\section{Univariable analysis}

Characteristic
Hazard ratio $(95 \% \mathrm{Cl})$

\section{Multivariable analysis}

$p$ value Characteristic

Hazard ratio

$p$ value $(95 \% \mathrm{Cl})$

\begin{tabular}{|c|c|c|c|c|c|}
\hline Age & & & Age & & \\
\hline$<50$ & Reference & & $<50$ & & \\
\hline$\geq 50$ & $1.04(0.86,1.25)$ & 0.715 & $\geq 50$ & & \\
\hline ECOG & & & ECOG & & \\
\hline 0 & Reference & & 0 & Reference & \\
\hline 1 & $1.23(0.96,1.59)$ & 0.099 & 1 & $1.12(0.87,1.44)$ & 0.397 \\
\hline 2 & $2.62(1.71,4.01)$ & 0.000 & 2 & $1.71(1.10,2.68)$ & 0.018 \\
\hline T-stage & & & T-stage & & \\
\hline T1 & Reference & & $\mathrm{T} 1$ & Reference & \\
\hline $\mathrm{T} 2$ & $1.17(0.92,1.47)$ & 0.197 & $\mathrm{~T} 2$ & $1.06(0.83,1.35)$ & 0.650 \\
\hline T3 & $1.51(1.01,2.26)$ & 0.044 & T3 & $1.15(0.75,1.75)$ & 0.522 \\
\hline T4 & $1.41(0.94,2.11)$ & 0.095 & T4 & $1.09(0.70,1.70)$ & 0.690 \\
\hline Unknown & $0.93(0.70,1.24)$ & 0.625 & Unknown & $0.94(0.67,1.31)$ & 0.708 \\
\hline $\mathrm{N}$-stage & & & $\mathrm{N}$-stage & & \\
\hline No & Reference & & NO & Reference & \\
\hline N1 & $1.17(0.90,1.52)$ & 0.241 & N1 & $1.10(0.84,1.43)$ & 0.510 \\
\hline N2 & $1.34(1.01,1.77)$ & 0.045 & $\mathrm{~N} 2$ & $1.14(0.84,1.54)$ & 0.393 \\
\hline N3 & $1.79(1.36,2.36)$ & 0.000 & N3 & $1.43(1.05,1.95)$ & 0.023 \\
\hline Unknown & $1.19(0.84,1.69)$ & 0.330 & Unknown & $1.10(0.73,1.66)$ & 0.645 \\
\hline \multicolumn{6}{|l|}{ M-stage } \\
\hline MO & Reference & & & & \\
\hline M1 & $1.15(0.89,1.49)$ & 0.296 & & & \\
\hline
\end{tabular}

Subtype

Subtype

OS overall survival, BCLM breast cancer lung metastases, Cl confidence interval, ECOG Eastern Cooperative Oncology Group, HR hormone receptor, HER2 human epidermal growth factor receptor 2. 


\begin{tabular}{|c|c|c|c|c|c|}
\hline \multicolumn{3}{|c|}{ Univariable analysis } & \multicolumn{3}{|c|}{ Multivariable analysis } \\
\hline $\mathrm{HR}+/ \mathrm{HER} 2-$ & \multicolumn{2}{|l|}{ Reference } & \multirow{2}{*}{$\begin{array}{l}\text { HR+/HER2- } \\
\text { HR-/HER2+ }\end{array}$} & \multicolumn{2}{|l|}{ Reference } \\
\hline HR-/HER2+ & $1.43(1.08,1.90)$ & 0.013 & & $1.44(1.07,1.94)$ & 0.016 \\
\hline HR+/HER2+ & $1.04(0.79,1.37)$ & 0.769 & HR+/HER2+ & $1.06(0.80,1.40)$ & 0.688 \\
\hline Triple-negative & $1.73(1.36,2.19)$ & 0.000 & Triple-negative & $1.96(1.52,2.52)$ & 0.000 \\
\hline \multicolumn{3}{|l|}{ Liver metastases } & \multicolumn{3}{|c|}{ Liver metastases } \\
\hline No & Reference & & No & Reference & \\
\hline Yes & $2.71(2.20,3.35)$ & 0.000 & Yes & $2.57(2.05,3.21)$ & 0.000 \\
\hline \multicolumn{6}{|l|}{ Brain metastases } \\
\hline No & \multicolumn{5}{|l|}{ Reference } \\
\hline Yes & $1.40(0.94,2.10)$ & 0.100 & & & \\
\hline \multicolumn{3}{|l|}{ Bone metastases } & \multicolumn{3}{|c|}{ Bone metastases } \\
\hline No & Reference & & No & Reference & \\
\hline Yes & $1.43(1.18,1.74)$ & 0.000 & Yes & $1.33(1.08,1.64)$ & 0.007 \\
\hline
\end{tabular}

\section{Discussion}

In this retrospective study, we described the clinicopathological characteristics and analyzed the prognosis of patients with synchronous lung metastases at initial MBC diagnosis in China. We identified 809 patients with BCLM upon newly diagnosis of MBC, accounting for $35.7 \%$ of all MBC patients. Compared with other groups, patients with triple-negative subtype had the highest percentage of lung metastases, consistent with previous findings [12-14]. The incidence of lung metastasis in triple-negative breast cancer (TNBC) could reach up to $40 \%$ [15], similar with $42.3 \%$ in our data. Additionally, the prognosis of BCLM patients differed remarkably in tumor subtypes, varying between 26.8 months of triple-negative subtype and 49.0 months of HR+/HER2- subtype.

Our study confirmed the results that TNBC was more aggressive and preferred to develop lung metastases. The molecular mechanisms underlying TNBC metastasis to lung might offer therapeutic targets for clinical prevention and management. Minn et al. [16] identified fascin as a mediator promoting basal-like breast cancer metastasis to lung, due to its close association with cell motility. Iriondo et al. [17] observed that inhibition of transforming growth factor- $\beta 1$-activated kinase- 1 (TAK1) could suppress lung metastasis in TNBC, which might provide a novel target for impairing TNBC lung metastasis. A single mutation on microrchidia family CW-type zinc finger 2 (MORC2) promoted TNBC lung metastasis 
by regulating heterogeneous nuclear ribonucleoprotein M (hnRNPM)- mediated CD44 splicing, which indicated that the knockdown of hnRNPM might reduce lung metastatic potential of TNBC cells with mutant MORC2 [18]. Another research revealed that the overexpression of transcription and export complex 2 subunit (ENY2) could promote TNBC progression and lung metastasis both in vitro and in vivo [19]. Further mechanisms clarifying TNBC lung metastasis are certainly worth exploring, which may provide potential targets for new drugs.

Our data also indicated that patients with older age and worse performance status were more likely to present with lung metastases at initial MBC diagnosis. The increasing risk of lung metastases associated with aging was consistently found in population-based studies $[6,20]$. On the contrary, previous studies observed that younger patients had a higher risk of liver metastases $[5,21]$. Interestingly, our study also revealed that patients with liver or bone metastases had lower odds of lung metastases at diagnosis. The predictive features associated with different metastatic sites may help clinicians distinguish patients with distinct organ-specific metastases during the clinical practice.

The BCLM patients in our data achieved a median OS of 41.7 months since MBC diagnosis, among which triple-negative subtype experienced the worst outcome of 26.8 months and HR+/HER2- subtype the best of 49.0 months. The prognosis of MBC patients varied remarkably by the metastatic organs, with the best for bone, followed by lung, liver and the worst for brain metastases [7, 22]. Previous findings recorded a survival ranging from 21.0 to 58.5 months in MBC patients with lung metastases $[1,6,23]$. A pulmonary metastasectomy study reported a median survival of 23.6 months in TNBC patients with an isolated and limited number of lung metastases, significantly poorer than HR + or HER2 + patients [24]. A population-based research showed that TNBC patients with metastases confined to lung had a median OS of only 14.0 months [25]. TNBC is still lethal and remains intractable to existing treatments, extremely desirable for novel therapies to improve the prognosis.

We also identified prognostic factors for survival of BCLM patients and found that worse performance status, later N-stage, HR-/HER2 + subtype, triple-negative subtype and the simultaneous presence of liver or bone metastases were significantly correlated with poor outcome. Multiple sites of first metastases had significantly unfavorable prognosis than single site first metastases [26, 27]. In our data, the extrapulmonary metastases of bone and liver had 1.33 and 2.57 times of mortality risk than lung-only metastases at MBC diagnosis, respectively. Brain metastases also worsen the outcome of BCLM patients but the difference did not reach significance, probably due to the late onset of brain metastases during the clinical course, with an incidence of only $6.90-7.56 \%$ in newly MBC diagnosis patients [27-29].

There were some limitations in our study. Firstly, discordance in tumor phenotype has been reported in multiple studies [30], but we did not have enough information on the receptor status of metastatic tumors, which might cause some bias in the analysis of incidence and survival outcomes when stratified by breast cancer subtype. Additionally, the number of lung lesions was an important risk factor for BCLM patients [31], but it was not documented in detail in our database. Finally, the retrospective nature of this research and relatively small population require future studies to confirm the results. 


\section{Conclusions}

Our study provides essential information on clinicopathological features and survival outcomes of BCLM patients at initial diagnosis of MBC in China. The risk factors identified here help to screen breast cancer patients with high odds of lung metastases and BCLM patients with high risk of mortality. The early detection of metastases and proper evaluation of prognosis in clinical practice are beneficial to optimize the disease outcomes.

\section{Abbreviations}

MBC

metastatic breast cancer; BCLM:breast cancer lung metastases; ECOG:Eastern Cooperative Oncology Group; OS:overall survival; IHC:immunohistochemistry; HR:hormone receptor; HER2:human epidermal growth factor receptor 2; FISH:fluorescent in-situ hybridization; AJCC:American Joint Committee on Cancer; OR:odds ratio; Cl:confidence interval; TNBC:triple-negative breast cancer; TAK1:transforming growth factor- $\beta 1$-activated kinase-1; MORC2:microrchidia family $\mathrm{CW}$-type zinc finger 2;

hnRNPM:heterogeneous nuclear ribonucleoprotein M; ENY2:transcription and export complex 2 subunit.

\section{Declarations}

\section{Ethics approval and consent to participate}

All methods were carried out in accordance with relevant guidelines and regulations. This work was approved by the institutional review board of National Cancer Center/National Clinical Research Center for Cancer/Cancer Hospital, Chinese Academy of Medical Sciences and Peking Union Medical College.

\section{Consent for publication}

The informed consent was obtained from all participants.

\section{Availability of data and materials}

The data used during the current study are available from the corresponding author on reasonable request.

\section{Competing interests}

The authors declare that they have no competing interests.

\section{Funding}

This study was supported by grants from National Key R\&D Program of China (2018YFC1312101) and Chinese Academic of Medical Sciences Initiative for Innovative Medicine (CAMS-12M-1-010). 


\section{Authors' contributions}

BX directed the study and was responsible for study design. SL performed the statistical analysis and drafted the initial manuscript. All authors collected clinical data. All authors read and approved the final manuscript.

\section{Acknowledgements}

Not applicable.

\section{References}

1. Wang R, Zhu Y, Liu X, Liao X, He J, Niu L. The Clinicopathological features and survival outcomes of patients with different metastatic sites in stage IV breast cancer. BMC Cancer 2019;19:1091.

2. Largillier R, Ferrero JM, Doyen J, Barriere J, Namer M, Mari V, et al. Prognostic factors in 1,038 women with metastatic breast cancer. Ann Oncol 2008;19:2012-9.

3. Friedel G, Pastorino U, Ginsberg RJ, Goldstraw P, Johnston M, Pass H, et al. Results of lung metastasectomy from breast cancer: prognostic criteria on the basis of 467 cases of the International Registry of Lung Metastases. Eur J Cardiothorac Surg 2002;22:335-44.

4. Diaz-Canton EA, Valero V, Rahman Z, Rodriguez-Monge E, Frye D, Smith T, et al. Clinical course of breast cancer patients with metastases confined to the lungs treated with chemotherapy. The University of Texas M.D. Anderson Cancer Center experience and review of the literature. Ann Oncol 1998;9:413-8.

5. Cummings MC, Simpson PT, Reid LE, Jayanthan J, Skerman J, Song S, et al. Metastatic progression of breast cancer: insights from 50 years of autopsies. J Pathol 2014;232:23-31.

6. Xiao W, Zheng S, Liu P, Zou Y, Xie X, Yu P, et al. Risk factors and survival outcomes in patients with breast cancer and lung metastasis: a population-based study. Cancer Med 2018;7:922-30.

7. Ording AG, Heide-Jørgensen U, Christiansen CF, Nørgaard M, Acquavella J, Sørensen HT. Site of metastasis and breast cancer mortality: a Danish nationwide registry-based cohort study. Clin Exp Metastasis 2017;34:93-101.

8. Medeiros B, Allan AL. Molecular Mechanisms of Breast Cancer Metastasis to the Lung: Clinical and Experimental Perspectives. Int J Mol Sci 2019;20.

9. Cardoso F, Senkus E, Costa A, Papadopoulos E, Aapro M, André F, et al. 4th ESO-ESMO International Consensus Guidelines for Advanced Breast Cancer (ABC 4)†. Ann Oncol 2018;29:1634-57.

10. Handy JR, Bremner RM, Crocenzi TS, Detterbeck FC, Fernando HC, Fidias PM, et al. Expert Consensus Document on Pulmonary Metastasectomy. Ann Thorac Surg 2019;107:631-49.

11. Lin S, Mo H, Li Y, Guan X, Chen Y, Wang Z, et al. Risk Factors and Survival of Patients With Liver Metastases at Initial Metastatic Breast Cancer Diagnosis in Han Population. Front Oncol 2021;11:670723. 
12. Rodríguez-Pinilla SM, Sarrió D, Honrado E, Hardisson D, Calero F, Benitez J, et al. Prognostic significance of basal-like phenotype and fascin expression in node-negative invasive breast carcinomas. Clin Cancer Res 2006;12:1533-9.

13. Soni A, Ren Z, Hameed O, Chanda D, Morgan CJ, Siegal GP, et al. Breast cancer subtypes predispose the site of distant metastases. Am J Clin Pathol 2015;143:471-8.

14. Jin L, Han B, Siegel E, Cui Y, Giuliano A, Cui X. Breast cancer lung metastasis: Molecular biology and therapeutic implications. Cancer Biol Ther 2018;19:858-68.

15. Foulkes WD, Smith IE, Reis-Filho JS. Triple-negative breast cancer. N Engl J Med 2010;363:1938-48.

16. Minn AJ, Gupta GP, Siegel PM, Bos PD, Shu W, Giri DD, et al. Genes that mediate breast cancer metastasis to lung. Nature 2005;436:518-24.

17. Iriondo $\mathrm{O}$, Liu Y, Lee G, Elhodaky M, Jimenez C, Li L, et al. TAK1 mediates microenvironment-triggered autocrine signals and promotes triple-negative breast cancer lung metastasis. Nat Commun 2018;9:1994.

18. Zhang FL, Cao JL, Xie HY, Sun R, Yang LF, Shao ZM, et al. Cancer-Associated MORC2-Mutant M276I Regulates an hnRNPM-Mediated CD44 Splicing Switch to Promote Invasion and Metastasis in TripleNegative Breast Cancer. Cancer Res 2018;78:5780-92.

19. Xie G, Yang H, Ma D, Sun $Y$, Chen $H, H u X$, et al. Integration of whole-genome sequencing and functional screening identifies a prognostic signature for lung metastasis in triple-negative breast cancer. Int J Cancer 2019;145:2850-60.

20. Chen MT, Sun HF, Zhao Y, Fu WY, Yang LP, Gao SP, et al. Comparison of patterns and prognosis among distant metastatic breast cancer patients by age groups: a SEER population-based analysis. Sci Rep 2017;7:9254.

21. Xie J, Xu Z. A Population-Based Study on Liver Metastases in Women with Newly Diagnosed Breast Cancer. Cancer Epidemiol Biomarkers Prev 2019;28:283-92.

22. Kast K, Link T, Friedrich K, Petzold A, Niedostatek A, Schoffer O, et al. Impact of breast cancer subtypes and patterns of metastasis on outcome. Breast Cancer Res Treat 2015;150:621-9.

23. Gerratana L, Fanotto V, Bonotto M, Bolzonello S, Minisini AM, Fasola G, et al. Pattern of metastasis and outcome in patients with breast cancer. Clin Exp Metastasis 2015;32:125-33.

24. Yhim HY, Han SW, Oh DY, Han W, Im SA, Kim TY, et al. Prognostic factors for recurrent breast cancer patients with an isolated, limited number of lung metastases and implications for pulmonary metastasectomy. Cancer 2010;116:2890-901.

25. Zhao HY, Gong Y, Ye FG, Ling H, Hu X. Incidence and prognostic factors of patients with synchronous liver metastases upon initial diagnosis of breast cancer: a population-based study. Cancer Manag Res 2018;10:5937-50.

26. Van Mechelen M, Van Herck A, Punie K, Nevelsteen I, Smeets A, Neven P, et al. Behavior of metastatic breast cancer according to subtype. Breast Cancer Res Treat 2020;181:115-25. 
27. Leone BA, Vallejo CT, Romero AO, Machiavelli MR, Pérez JE, Leone J, et al. Prognostic impact of metastatic pattern in stage IV breast cancer at initial diagnosis. Breast Cancer Res Treat 2017;161:537-48.

28. Martin AM, Cagney DN, Catalano PJ, Warren LE, Bellon JR, Punglia RS, et al. Brain Metastases in Newly Diagnosed Breast Cancer: A Population-Based Study. JAMA Oncol 2017;3:1069-77.

29. Zhao W, Wu L, Zhao A, Zhang M, Tian Q, Shen Y, et al. A nomogram for predicting survival in patients with de novo metastatic breast cancer: a population-based study. BMC Cancer 2020;20:982.

30. Schrijver W, Suijkerbuijk KPM, van Gils CH, van der Wall E, Moelans CB, van Diest PJ. Receptor Conversion in Distant Breast Cancer Metastases: A Systematic Review and Meta-analysis. J Natl Cancer Inst 2018;110:568-80.

31. Chen F, Fujinaga T, Sato K, Sonobe M, Shoji T, Sakai H, et al. Clinical features of surgical resection for pulmonary metastasis from breast cancer. Eur J Surg Oncol 2009;35:393-7.

\section{Figures}




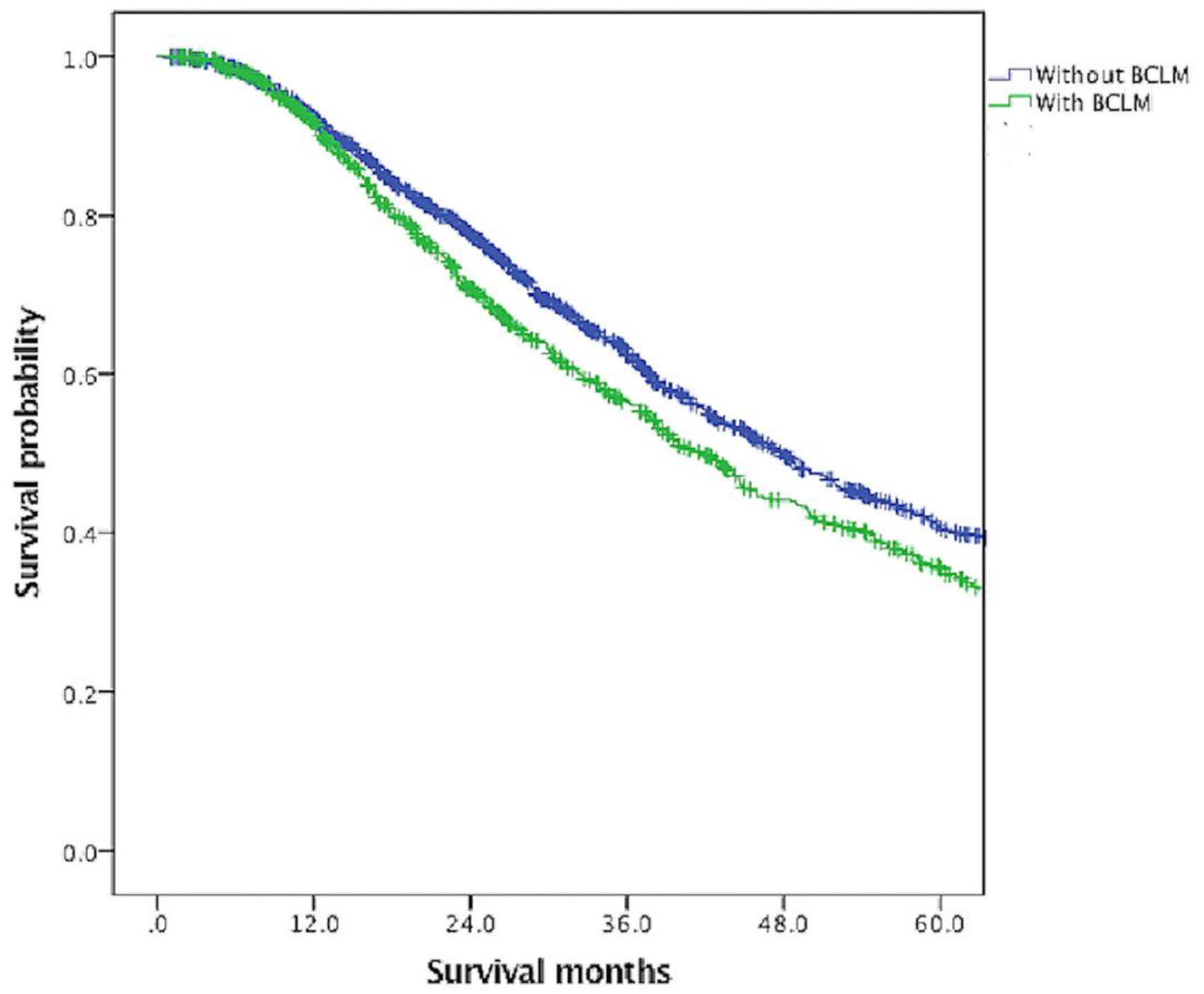

Figure 1

Overall survival of metastatic breast cancer patients with or without BCLM. BCLM, breast cancer lung metastases. 


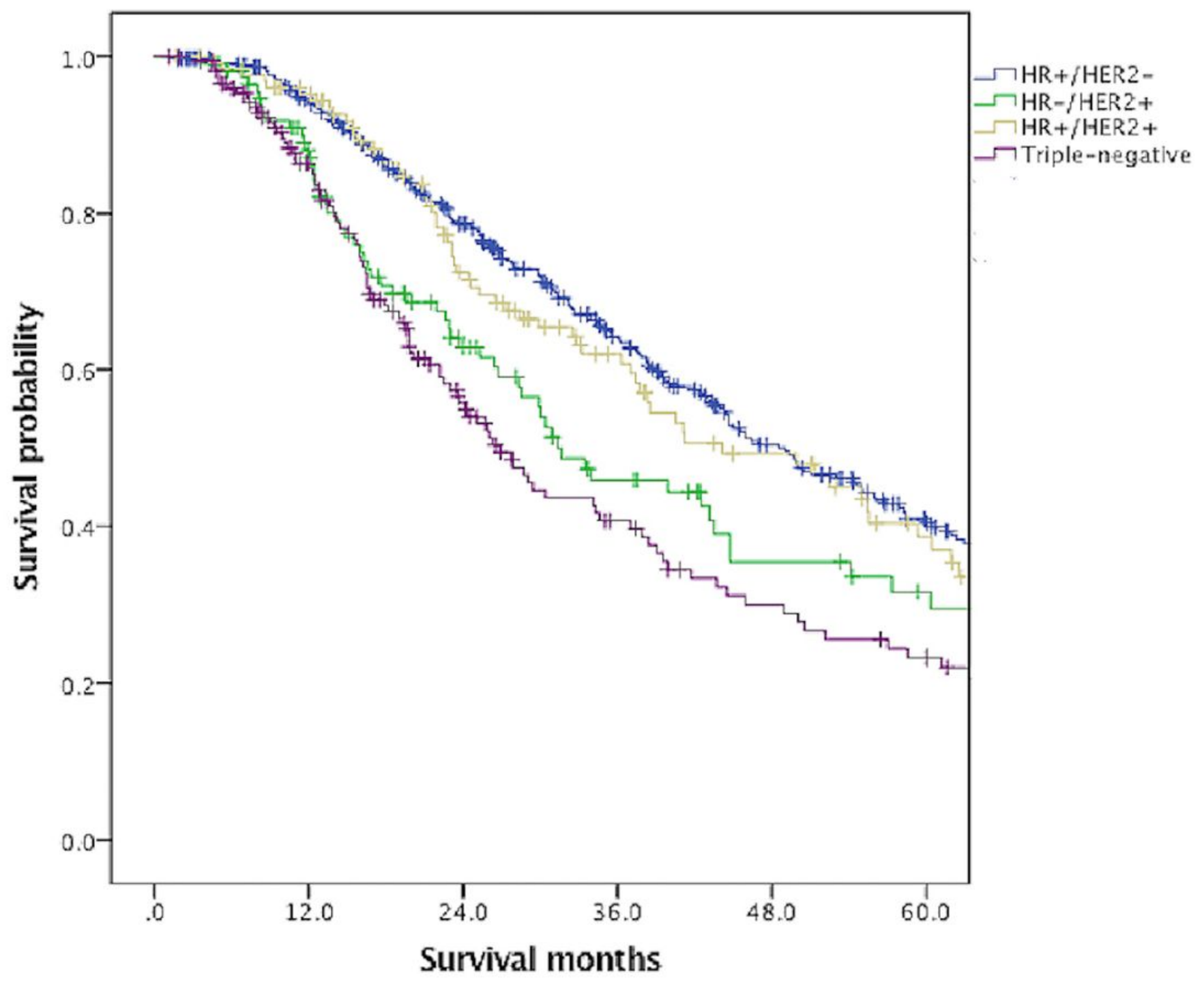

Figure 2

Overall survival of BCLM patients according to breast cancer subtype. BCLM, breast cancer lung metastases, HR, hormone receptor, HER2, human epidermal growth factor receptor 2. 